\title{
REVIEW
}

\section{Rationale for revision and proposed changes of the WHO diagnostic criteria for polycythemia vera, essential thrombocythemia and primary myelofibrosis}

\author{
T Barbui ${ }^{1,5}$, J Thiele ${ }^{2,5}$, AM Vannucchi ${ }^{3,5}$ and A Tefferi ${ }^{4,5}$
}

The 2001/2008 World Health Organization (WHO)-based diagnostic criteria for polycythemia vera (PV), essential thrombocythemia (ET) and primary myelofibrosis (PMF) were recently revised to accomodate new information on disease-specific mutations and underscore distinguishing morphologic features. In this context, it seems to be reasonable to compare first major diagnostic criteria of the former WHO classifications for myeloproliferative neoplasm (MPN) and then to focus on details that have been discussed and will be proposed for the upcoming revision of diagnostic guidelines. In PV, a characteristic bone marrow (BM) morphology was added as one of three major diagnostic criteria, which allowed lowering of the hemoglobin/hematocrit threshold for diagnosis, which is another major criterion, to $16.5 \mathrm{~g} / \mathrm{dl} / 49 \%$ in men and $16 \mathrm{~g} / \mathrm{dl} / 48 \%$ in women. The presence of a JAK2 mutation remains the third major diagnostic criterion in PV. Subnormal serum erythropoietin level is now the only minor criterion in PV and is used to capture JAK2-unmutated cases. In ET and PMF, mutations that are considered to confirm clonality and specific diagnosis now include CALR, in addition to JAK2 and MPL. Also in the 2015 discussed revision, overtly fibrotic PMF is clearly distinguished from early/prefibrotic PMF and each PMF variant now includes a separate list of diagnostic criteria. The main rationale for these changes was to enhance the distinction between so-called masked PV and JAK2-mutated ET and between ET and prefibrotic early PMF. The proposed changes also underscore the complementary role, as well as limitations of mutation analysis in morphologic diagnosis. On the other hand, discovery of new biological markers may probably be expected in the future to enhance discrimination of the different MPN subtypes in accordance with the histological BM patterns and corresponding clinical features.

Blood Cancer Journal (2015) 5, e337; doi:10.1038/bcj.2015.64; published online 14 August 2015

Following the $2001^{\text {(ref. 1) }}$ and $2007 / 2008^{\text {(refs. 2-4) }}$ updated classifications of myeloproliferative neoplasms (MPNs) by the World Health Organization (WHO) a number of clinical-pathological studies have documented the usefulness of these relevant diagnostic criteria. ${ }^{5-11}$ However, lively discussion and occasionally controversy persist as concerns not only the reliability of the proposed clinical features required for WHO-defined diagnosis, but particularly the diagnostic relevance as well as the reproducibility of bone marrow (BM) morphology criteria. ${ }^{12-16}$

Moreover, recently evolving molecular features yielded new perspectives and provided novel insights for the understanding 'of the pathobiology of MPN. In this context, the discovery of calreticulin (CARL) mutations occurring in JAK2- and MPL-negative essential thrombocythemia (ET) and primary myelofibrosis (PMF) ${ }^{17,18}$ facilitated diagnostic precision and may also harbor prognostic relevance. ${ }^{19}$

Overall, in consideration of the new molecular findings and experiences gained in the past years, there is a rationale to make proposals for the upcoming revision of diagnostic guidelines that are going to be published in the near future.

The set of the reasons on which a WHO revision is suggested are the following:

(1) The description of novel molecular findings other than Janus kinase (JAK2V617F) and myeloproliferative leukemia virus oncogene (MPL) mutations that deserve diagnostic importance for all the three major entities.

(2) In polycythemia vera (PV), the possibility of an underdiagnosis as the consequence of applying the former hemoglobin $(\mathrm{Hb})$ or hematocrit (Hct) threshold values and the emerging role of BM morphology as a major criterion.

(3) In ET, the need to differentiate 'true $\mathrm{ET}^{\prime}$ from prefibrotic/early primary PMF (prePMF) by emphasizing the lack of reticulin fibrosis at onset, owing that such distinction has prognostic implications.

(4) In PMF, the challenge of defining more explicitly minor clinical criteria that may have major impact not only on accurate diagnosis but also on prognosis.

Altogether it seems to be reasonable to compare major diagnostic criteria of the former WHO classifications for $\mathrm{MPN}^{1-4}$ starting from 2001, and then to focus on details suggested for the upcoming revision of diagnostic guidelines that, however, have not been published yet and therefore should be regarded as proposals.

\section{MUTATIONS AND THEIR DIAGNOSTIC AND PROGNOSTIC UTILITY}

From 2005 onwards, more than 20 somatic mutations have been described in MPN. ${ }^{20}$ The first mutation described (that is,

\footnotetext{
THematology and Research Foundation, Papa Giovanni XXIII Hospital, Bergamo, Italy; ${ }^{2}$ Institute of Pathology, University of Cologne, Cologne, Germany; ${ }^{3}$ Department of Experimental and Clinical Medicine, Azienda Ospedaliera-Universitaria Careggi, University of Florence, Florence, Italy and ${ }^{4}$ Hematology Division, Mayo Clinic, Rochester, MN, USA. Correspondence: Dr T Barbui, Hematology and Research Foundation, Ospedale Papa Giovanni XXIII, Piazza O.M.S., 1, 24127 Bergamo, Italy.

E-mail: tbarbui@hpg23.it

${ }^{5}$ These authors contributed equally to this work.

Received 18 June 2015; accepted 30 June 2015
} 
JAK2V617F), which is also the most frequent, involves Janus kinase 2 (JAK2 located on chromosome 9p24). ${ }^{21}$ JAK2V617F mutational frequency is estimated at $97 \%$ in PV, $50-60 \%$ in ET and $55-65 \%$ in PMF. ${ }^{20}$ However, JAK2V617F is not specific to MPN and is also seen in less than $5 \%$ of patients with acute myeloid leukemia, myelodysplastic syndromes (MDS), chronic myelomonocytic leukemia and other myeloid malignancies. ${ }^{22}$ Of note, JAK2V617F mutational frequency as high as $50 \%$ has been reported in the MDS/MPN overlap syndrome of refractory anemia with ring sideroblasts associated with marked thrombocytosis. ${ }^{3}$ Subsequent to the discovery of JAK2V617F, other JAK2 mutations (for example, $J A K 2$ exon 12 mutations) were described in JAK2-unmutated PV and characterized by predominantly erythroid myelopoiesis. ${ }^{23,24}$ JAK2 mutations are not present in the normal control population and in patients with non-clonal erythrocytosis or thrombocytosis. ${ }^{25}$ Accordingly, JAK2 mutation screening was adopted, as a useful clonal marker, by the WHO system of hematopoietic tumor classification, in its 2008 revised document. ${ }^{3,4}$ In routine clinical practice, the absence of a JAK2 mutation makes the diagnosis of PV unlikely but its presence cannot, by itself, distinguish PV from ET or PMF, thus the need for BM examination. Rare cases of JAK2-unmutated 'PV' have been associated with $L_{N K}{ }^{26}$

The second most frequent mutations in MPN involve the CALRgene located on chromosome 19p13.2. ${ }^{18,19}$ With the exception of isolated reports, ${ }^{27}$ CALR mutations are absent in PV, whereas their frequencies are estimated at $20-25 \%$ in ET and $\mathrm{PMF}^{28}$ therefore, CALR mutations appear to be relatively specific to ET and PMF. The third MPN-specific mutation involves the myeloproliferative leukemia virus oncogene (MPL; located on chromosome 1p34) and has been described in 3\% of patients with ET and $7 \%$ of those with PMF, and only rarely in PV. ${ }^{29,30} J A K 2, C A L R$ and MPL mutations are often mutually exclusive, although concurrent occurrence has been reported, likely as the result of concurrent individual mutated clones. ${ }^{31}$ Taken together, approximately $99 \%$ of PV patients are expected to harbor JAK2 mutations, whereas $80-90 \%$ of patients with ET or PMF carry one of the three 'MPN-driver' mutations: JAK2, CALR or MPL. It was therefore appropriate to suggest that the upcoming revision of the WHO system in addition to JAK2 includes CALR and MPL mutation screening (Tables 1-4) in the diagnostic process for JAK2-unmutated ET and PMF. ${ }^{28}$ Once again, BM examination is often necessary for accurate diagnosis since JAK2/CALR/MPL mutation screening, by itself, cannot distinguish masked PV from JAK2-mutated ET, WHOdefined ET from prefibrotic/early PMF or triple-negative ET from other causes of thrombocytosis. The latter stems from the fact that about $10-15 \%$ of patients with ET or PMF lacks all three MPN driver mutations and are referred to as being 'triple-negative'. ${ }^{19}$ In JAK2/CALR/MPL-mutated patients, mutant allele burden is sometimes helpful in further clarifying the specific diagnosis; for example, higher than $40 \%$ JAK2 mutant allele burden is unusual in ET and suggests either masked PV or prefibrotic/early PMF. ${ }^{32}$

$J A K 2 / C A L R / M P L$ mutations also provide important prognostic information in MPN. A low JAK2V617F allele burden in PMF has been associated with worse prognosis, ${ }^{33,34}$ whereas a higher than $50 \%$ JAK2V617F allele burden in PV has been associated with increased risk of fibrotic transformation. ${ }^{35}$ Also in PV, a higher JAK2 mutant allele burden has been associated with pruritus. ${ }^{36}$ In ET and PMF, JAK2 mutations are associated with older age, higher hemoglobin level, leukocytosis and lower platelet count and, in ET, an increased risk of thrombosis (compared to those with CALR mutation or triple-negative mutational status). ${ }^{37}$ Similarly, CALR mutations in ET and PMF have been associated with younger age and higher platelet count whereas their effect on $\mathrm{Hb}$ and leukocyte count appears to be different in ET (lower $\mathrm{Hb}$ and leukocyte count) versus PMF (higher $\mathrm{Hb}$ and leukocyte levels). ${ }^{28}$ Furthermore, among CALR-mutated ET patients, those with type 2 variant CALR mutation (a 5-bp TTGTC insertion; p.K385fs*47), compared to those with type 1 variant (a 52-bp deletion; p.L367fs*46) display higher platelet counts. ${ }^{38}$ More importantly, in PMF, the presence of type 1 or type 1-like CALR mutations has been associated with superior survival. ${ }^{39}$

Several other mutations in MPN are neither sensitive nor specific enough to warrant their consideration in the initial diagnostic process for MPN. ${ }^{40}$ The most frequent among these are ASXL1 (Additional Sex Combs-Like 1), TET2 (TET oncogene family

Table 1. Evolution of the WHO diagnostic guidelines for MPN between 2001 and 2015

\begin{tabular}{|c|c|c|c|}
\hline & WHO criteria 2001 & WHO criteria 2008 & $\begin{array}{l}\text { Proposed WHO criteria } 2015 \\
\text { (adapted with minor modifications) }\end{array}$ \\
\hline \multicolumn{4}{|l|}{ Polycythemia vera (PV) } \\
\hline Hemoglobin, g/dl & $\begin{array}{l}\text { A1 }->18.5 \text { in men } \\
>16.5 \text { in women }\end{array}$ & $\begin{array}{l}\text { A1 }->18.5 \text { in men } \\
>16.5 \text { in women }\end{array}$ & $\begin{array}{l}\text { A1 }->16.5 \text { in men } \\
>16.0 \text { in women }\end{array}$ \\
\hline $\begin{array}{l}\text { Red cell mass } \\
\text { Hematocrit, \% }\end{array}$ & $\begin{array}{l}\text { or } \\
\text { increased }\end{array}$ & $\begin{array}{l}\text { or } \\
\text { increased } \\
\text { increased }\end{array}$ & $\begin{array}{l}\text { or } \\
\text { increased } \\
>49 \% \text { in men } \\
>48 \% \text { in women }\end{array}$ \\
\hline Secondary erythrocytosis & A2 - no evidence & & \\
\hline Splenomegaly & A3 - yes/no & & \\
\hline Clonal genetic abnormality & A4 - yes/no & $\begin{array}{l}\text { A2 - JAK2 V617F or } \\
\text { JAK2 exon } 12 \text { mutation }\end{array}$ & A3 - JAK2 mutation \\
\hline Endogenous erythroid colony formation & & B3 - yes/no & \\
\hline Thrombocytosis $>400 \times 10^{9} / \mathrm{I}$ & A5 - yes/no & & \\
\hline Subnormal serum erythropoietin level & & B2 - yes/no & B - yes/no \\
\hline White blood cell counts $>12 \times 10^{9} / \mathrm{I}$ & B2 - yes/no & & \\
\hline Bone marrow (BM) histology & $\begin{array}{l}\text { B3 - BM with panmyelosis } \\
\text { showing prominent erythroid } \\
\text { and megakaryocytic } \\
\text { proliferation }\end{array}$ & $\begin{array}{l}\text { B1 - BM with age-adjusted } \\
\text { hypercellularity and } \\
\text { trilineage growth } \\
\text { (panmyelosis) }\end{array}$ & $\begin{array}{l}\text { A2 - BM with age-adjusted } \\
\text { hypercellularity and trilineage } \\
\text { growth (panmyelosis) with } \\
\text { pleomorphic, mature } \\
\text { megakaryocytes }\end{array}$ \\
\hline Diagnosis of $\mathrm{PV}$ requires & $\begin{array}{l}A 1+A 2 \text { and any other category } \\
A \text { or } A 1+A 2 \text { and any two of } \\
\text { category } B\end{array}$ & $\begin{array}{l}A 1+A 2 \text { and one } B \text { criterion } \\
\text { or } A 1+\text { two } B \text { criteria }\end{array}$ & $A 1-3$ or $A 1+2$ and the $B$ criterion \\
\hline
\end{tabular}


Table 2. Evolution of the WHO diagnostic guidelines for MPN between 2001 and 2015

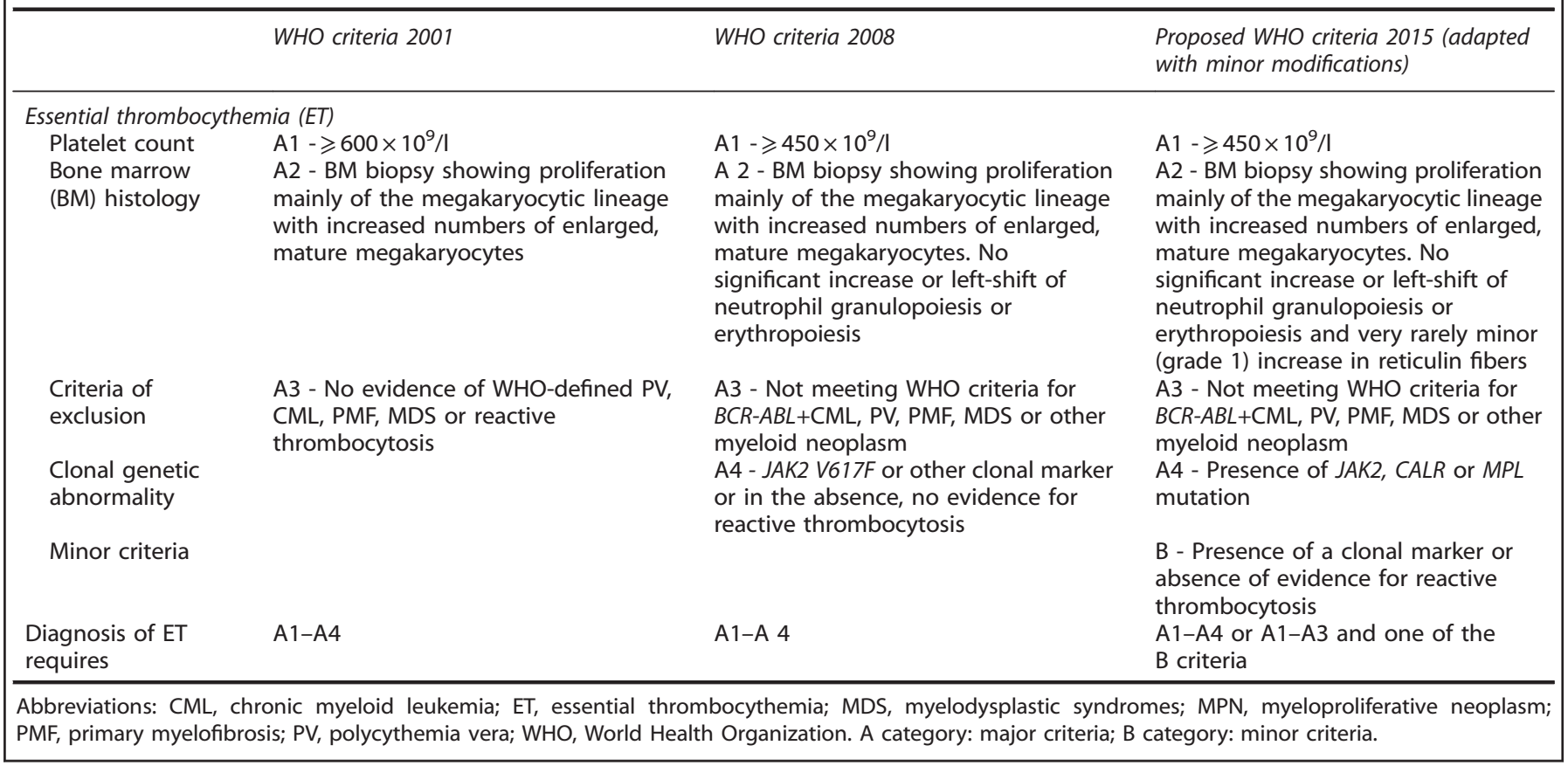

Table 3. Evolution of the WHO diagnostic guidelines for MPN between 2001 and 2015

\begin{tabular}{|c|c|c|c|}
\hline \multicolumn{4}{|c|}{ Prefibrotic/early primary myelofibrosis (prePMF) } \\
\hline $\begin{array}{l}\text { Criteria of } \\
\text { exclusion }\end{array}$ & & $\begin{array}{l}\text { A2 - Not meeting WHO criteria for } \\
B C R-A B L+C M L, \text { MDS or other myeloid } \\
\text { neoplasm }\end{array}$ & $\begin{array}{l}\text { A2 - Not meeting WHO criteria for } \\
B C R-A B L+C M L, P V, E T, M D S \text { or other } \\
\text { myeloid neoplasm }\end{array}$ \\
\hline $\begin{array}{l}\text { Clonal genetic } \\
\text { abnormality }\end{array}$ & & $\begin{array}{l}\text { A3 - JAK2 V617F or other clonal marker } \\
\text { (MPL) or in the absence, no evidence } \\
\text { for reactive fibrosis }\end{array}$ & $\begin{array}{l}\text { A3 - Presence of } J A K 2, C A L R \text { or MPL } \\
\text { mutation or in the absence, presence } \\
\text { of an other clonal marker }{ }^{\mathrm{b}} \text { or no } \\
\text { evidence for reactive reticulin fibrosis }\end{array}$ \\
\hline $\begin{array}{l}\text { Diagnosis of } \\
\text { prePMF requires }\end{array}$ & $\begin{array}{l}\text { All criteria without further } \\
\text { specification }\end{array}$ & $\mathrm{A} 1-\mathrm{A} 3$ and two of the $\mathrm{B}$ criteria & $\begin{array}{l}\mathrm{A} 1-\mathrm{A} 3 \text { and at least one of the } \mathrm{B} \\
\text { criteria }\end{array}$ \\
\hline \multicolumn{4}{|c|}{$\begin{array}{l}\text { Abbreviations: CML, chronic myeloid leukemia; ET, essential thrombocythemia; } \mathrm{LDH} \text {, serum lactate dehydrogenase increased to above upper normal limit of } \\
\text { institutional reference range; MDS, myelodysplastic syndromes; MPN, myeloproliferative neoplasm; PV, polycythemia vera; WHO, World Health Organization. } \\
\text { A category: major criteria; B category: minor criteria. aln the absence of any of the three major clonal mutations, the search for the most frequent } \\
\text { accompanying mutations (ASXL1, EZH2, TET2, IDH1/IDH2, SRSF2, SF3B1) is of help in determining the clonal nature of the disease. }{ }^{b} \text { Minor bone marrow reticulin } \\
\text { fibrosis secondary to infection, autoimmune disorder or other chronic inflammatory conditions, hairy cell leukemia or other lymphoid neoplasm, metastatic } \\
\text { malignancy or toxic (chronic) myelopathies. }\end{array}$} \\
\hline
\end{tabular}

member 2), SRSF2 (serine/arginine-rich splicing factor 2) and U2AF1 (U2 Small Nuclear RNA Auxiliary Factor 1) and the less frequent IDH1/IDH2 (isocitrate dehydrogenase 1 and 2), TP53 (tumor protein p53), DNMT3A (DNA cytosine methyltransferase 3a), IKZF1 (IKAROS family zinc finger 1), LNK (SH2B3), SF3B1 (splicing factor $3 B$ subunit 1), EZH2 (enhancer of zeste homolog 2), CBL (Casitas B-lineage lymphoma proto-oncogene) and SETBP1 (SET binding protein 1). ${ }^{40-42}$ Interestingly, as reported also for JAK2 
Table 4. Evolution of the WHO diagnostic guidelines for MPN between 2001 and 2015

Primary myelofibrosis (PMF)

Bone marrow $\quad$ BM biopsy with decreased cellularity, dilated (BM) histology marrow sinuses with intraluminal hematopoiesis, prominent megakaryocytic proliferation and atypia (clustering, abnormally lobulated nuclei, naked nuclei), reticulin and/or collagen fibrosis, new bone formation (osteosclerosis)

Criteria of

exclusion

Clonal genetic

abnormality

Clinical findings

Moderate to marked anemia,low,normal or elevated WBC, platelet count low,normal or elevated, moderate to marked spleno-or hepatomegaly, leukoerythroblastosis, prominent red blood cell poikilocytosis with dacryocytes

Diagnosis of prePMF requires
A1 - BM biopsy showing megakaryocytic proliferation and atypia, usually accompanied by either reticulin or collagen fibrosis

A2 - Not meeting WHO criteria for $B C R-A B L+C M L$, MDS or other myeloid neoplasm A3 - JAK2 V617F or other clonal marker (MPL) or in the absence, no evidence for reactive fibrosis $^{\mathrm{a}}$

\section{B - criteria}

(1) Leukoerythroblastosis

(2) LDH increase

(3) Anemia

(4) Splenomegaly

$A 1-A 3$ and two of the B criteria
A1 - BM biopsy showing megakaryocytic proliferation and atypia accompanied by either reticulin or collagen fibrosis grades 2 or 3

A2 - Not meeting WHO criteria for $B C R-A B L+C M L$, PV, ET, MDS or other myeloid neoplasm A3 - Presence of JAK2, CALR or MPL mutation or in the absence, presence of another clonal marker $^{\mathrm{b}}$ or no evidence for reactive reticulin fibrosis ${ }^{a}$

B - criteria

(1) Anemia

(2) Leukocytosis $>11 \mathrm{~K} / \mu \mathrm{l}$

(3) Palpable splenomegaly

(4) $\mathrm{LDH}$ increase

(5) Leukoerythroblastosis $\mathrm{A} 1-\mathrm{A} 3$ and at least one of the $\mathrm{B}$ criteria

Abbreviations: $\mathrm{CML}$, chronic myeloid leukemia; ET, essential thrombocythemia; $\mathrm{LDH}$, serum lactate dehydrogenase increased to above upper normal limit of institutional reference range; MDS, myelodysplastic syndromes; MPN, myeloproliferative neoplasm; PV, polycythemia vera; WBC, white blood cell count; WHO, World Health Organization. A category: major criteria; B category: minor criteria. ${ }^{a}$ In the absence of any of the three major clonal mutations, the search for the most frequent accompanying mutations (ASXL1, EZH2, TET2, IDH1/IDH2, SRSF2, SF3B1) is of help in determining the clonal nature of the disease. ${ }^{\mathrm{b}} \mathrm{Bone}$ marrow fibrosis secondary to infection, autoimmune disorder or other chronic inflammatory conditions, hairy cell leukemia or other lymphoid neoplasm, metastatic malignancy or toxic (chronic) myelopathies.

some of these mutations (for example, TET2, ASXL1 and DNMT3A) were recently shown to occur in 'normal' elderly individuals (up to $5-6 \%$ in people older than 70 years). ${ }^{43-45}$ Regardless, in PMF, ASXL1, SRSF2, EZH2, IDH1/2 and U2AF1 mutations, as well as the number of such mutations in an individual patient, have been associated with shortened survival. ${ }^{42,46}$ Finally, in terms of pathogenetic mechanisms, JAK2 and MPL mutations are believed to drive myeloproliferation through direct activation of JAK-STAT, whereas megakaryocytes might be the primary target for CALR mutations that at least in part may still signal through the JAK/ STAT pathway. ${ }^{47}$ Furthermore, most recently, the phenotypepatterning effect of concurrently occurring multiple mutations and their order of acquisition has been suggested. ${ }^{47-49}$

\section{POLYCYTHEMIA VERA}

The key diagnostic issue in PV is which red cell parameters $(\mathrm{Hb}, \mathrm{Hct})$ may be more conveniently used as a surrogate of an increased red cell mass as measured by the isotope test. ${ }^{12,50-54}$ According to the $2007 / 2008$ updated WHO classification, ${ }^{2-4}$ the first major diagnostic criterion requires one of the following four components: $\mathrm{Hb}$ level $>18.5 \mathrm{~g} / \mathrm{dl}$ in men and $>16.5 \mathrm{~g} / \mathrm{dl}$ in women or red cell mass that is $>25 \%$ above mean normal predicted, or $\mathrm{Hb}$ level $>17 \mathrm{~g} / \mathrm{dl}$ in men $(>15 \mathrm{~g} / \mathrm{dl}$ in women) associated with a sustained increase of $\geqslant 2 \mathrm{~g} / \mathrm{dl}$ from baseline that cannot be attributed to correction of iron deficiency. Altogether it has been argued that application of these criteria may result in an underdiagnosis of PV by excluding patients with actual red cell mass that is $25 \%$ above mean predicted value, but whose $\mathrm{Hb}$ and Hct levels are below the WHO guidelines. ${ }^{49-56}$ Recently, the term masked PV ( $\mathrm{mPV}$ ) was re-introduced ${ }^{57}$ for JAK2-mutated patients with latent (initial, occult pre-polycythemic) disease manifestations who present with a BM morphology consistent with PV and display persistently raised $\mathrm{Hb}$ levels between 16.0 and $18.5 \mathrm{~g} / \mathrm{dl}$ for men and 15.0 and $16.5 \mathrm{~g} / \mathrm{dl}$ for women. Subsequently, a Hb level of $16.5 \mathrm{~g} / \mathrm{dl}$ in men and $16.0 \mathrm{~g} / \mathrm{dl}$ for women or in accordance with the BCSH criteria, ${ }^{58}$ a Hct level of $49 \%$ in men and $48 \%$ in women was determined to be the optimal cutoff levels for distinguishing JAK2-mutated ET from mPV. ${ }^{59,60}$ These data were entered in the new proposal for the $\mathrm{WHO}^{28}$ and accordingly shown in Table 1. The clinical relevance of recognizing $\mathrm{MPV}$ was demonstrated in a recent study on 66 JAK2-mutated patients younger than 40 years who revealed a higher risk of thrombosis compared with a control group of 97 cases with overt PV due to the less frequent use of phlebotomies or cytoreductive treatment. ${ }^{61}$ Altogether based on these clinical findings and the fact that BM morphology is superimposable to that of overt $\mathrm{PV}_{1}^{62}$ according to the original 2008 criteria, $^{3,4}$ it makes little sense that the term mPV is maintained, because it may be argued that this entity is in fact fully consistent with PV. Finally, the use of the endogenous erythroid colony growth assay was discarded as a minor diagnostic criterion ${ }^{28}$ due to limited practicability (time consuming, no standardization, restricted to specialized institutions, costly).

Concerning BM morphology in PV there is still some discussion regarding its diagnostic validity and particularly the impact in discriminating PV from other MPN entities. ${ }^{16,50,55}$ Contrasting this criticism unique characteristics pointing to both early and overt manifestations of disease have been demonstrated by several groups. ${ }^{56,57,63-66}$ Histopathology of the BM includes usually an age-adjusted hypercellularity ${ }^{67}$ due to tri-lineage proliferation (panmyelosis) including erythro-granulo-and megakaryopoiesis. In former studies by the Polycythemia Vera Study Group (PVSG) wide ranges (35-100\%) of hematopoietic cellularity were described, ${ }^{68}$ however, without regarding explicitly agematched reference values. ${ }^{67}$ Very important is that in PV megakaryopoiesis presents without significant morphological abnormalities but conspicuous differences in size (pleomorphy). 
In a recent study, differentiation between PV and ET seems to pose significant problems revealing a low sensitivity of histological diagnosis. ${ }^{16} \mathrm{~A}$ surprisingly high frequency of unclassifiable MPN (23-28\% compared with $10-15 \%$ or even less in other studies), ${ }^{5,66,69}$ an incomplete description of megakaryocyte nuclei atypia (failure to include clumsy/cloud-like abnormalities as key feature of atypia), ${ }^{70-73}$ but particular a very low reproducibility of fiber grading was in sharp contrast with previously reported findings. ${ }^{74}$ In regard to BM fibers, a minor increase in reticulin fibrosis at diagnosis of PV was reported in less than $20 \%$ of biopsy specimens by several groups, ${ }^{75-78}$ probably related to duration of the disease process preceding diagnostic BM biopsy examination. Concerning the PVSG cohort of PV patients $25 \%$ showed a slight and $11 \%$ a moderate to marked increase in reticulin. ${ }^{68,79}$ An increase in reticulin in PV has been associated with worse clinical outcome associated with a more rapid progression to post-PV myelofibrosis. ${ }^{78}$ For this reason, a BM biopsy may even be recommended in cases presenting with sustained absolute erythrocytosis $(\mathrm{Hb}$ levels $>18.5 \mathrm{~g} / \mathrm{dl}$ in men-Hct $55.5 \%$ or $>16.5 \% \mathrm{~g} / \mathrm{dl}$ in women-Hct $49.5 \%)$ together with all the other criteria (Table 1). Finally, several groups of hematopathologists have validated the specific histological BM pattern characterizing $\mathrm{PV}^{56,57,62-66}$ and confirmed and extended the notion that there are no significant differences regarding BM morphology between $\mathrm{mPV}$ and overt stages of PV. Based on data, BM morphology as essentially defined by the WHO classification ${ }^{3,4}$ was promoted to a major criterion in the proposed set of diagnostic criteria.

\section{ESSENTIAL THROMBOCYTHEMIA}

Concerning ET the obvious need to lower the diagnostic threshold level for the platelet value originally introduced by the PVSG ${ }^{80}$ has been recognized not only by the 2007/2008 updated WHO classification, ${ }^{3,4}$ but also by the BCSH (Table 2). ${ }^{13,14}$ Ample evidence has been produced that the arbitrarily chosen limit for a sustained platelet count of $600 \times 10^{9} / /$ by the PVSG ${ }^{80}$ fails to consider patients with initial ET associated with a lower degree of thrombocythemia, who may occasionally present with relevant thromboembolic or hemorrhagic complications. ${ }^{2,81-83}$ Moreover, many investigators have effectively argued that the use of such a high threshold value is not consistent with the 95th percentile for the normal platelet count adjusted for gender and race being below $400 \times 10^{9} /$. $^{2,84}$ For this reason, a cutoff level of $450 \times 10^{9} / \mathrm{I}$ was proposed in the diagnostic guidelines by the WHO and $\mathrm{BCSH}^{2,3,13,14}$ in particular when associated with clinical signs and symptoms that are usually not encountered in reactive thrombocytosis. ${ }^{85,86}$ Concerning the other hematological parameters in accordance with the BM features (Table 2) in more than 1150 patients with strictly WHO-defined ET collected in three centers, leuko- or erythrocytosis was an unusual finding as well as the occurrence of palpaple splenomegaly or increased levels of lactate dehydrogenase (LDH) while leukoerythroblastosis or poikilocytosis was absent. ${ }^{5,6}$

In comparison with the 2007/2008 updated WHO criteria, ${ }^{3,4}$ in ET the BM features have not to be changed significantly by the new proposals but there is the need to define more clearly the differentiation from prePMF. In this regard, the predominance of large to giant, mature megakaryocytes with hyperlobulated nuclei and a random distribution or loose clustering within the BM space without significant atypia is emphasized (Table 2). According to our experience and that of others it seems to be necessary to highlight explicitly that there is usually no or very rarely, less than $5 \%$, a minor-grade $1^{\text {(ref. }}$ 67) increase in reticulin fibers in WHOdefined ET at onset ${ }^{5,6,70,75-77}$ to avoid any confusion with PMF as has been reported. ${ }^{87-89}$ This is an important finding to reduce possible shortcomings attributed to subjectivity in interpreting BM morphology, standardization of prominent BM parameters is a key issue $\mathrm{e}^{70,90}$ and an essential feature, especially in PV cases presenting clinically with an ET-like appearance. ${ }^{63-65}$ The attempted aim is to generate a histological pattern characterizing the different subtypes of MPN. ${ }^{71}$ Overall application of the WHO-defined BM criteria on larger cohorts of patients either blindly or as explicitly postulated, in context with clinical data has resulted in consensus rates ranging between $73 \%$ and more than $90 \%$ largely depending on study design (all subtypes of MPN, inclusion of control cases with reactive changes, restriction to single BM parameters or only ET versus PMF, blinded evaluation or consideration of clinical data). ${ }^{5,6,66,69,72,73}$ On the other hand, several groups ${ }^{16,87,88,91,92}$ failed to reproduce the WHO diagnostic guidelines to a sufficient extend for a variety of reasons that have been reviewed and detailed ${ }^{15}$ or previously discussed in context with PV. ${ }^{16}$ Among others these included, failing standardization of BM features, inability of morphological pattern recognition, accurate fiber grading or small biopsy specimens. In this context, it has to be conceded that up to $10-15 \%$ of patients may present with MPN unclassifiable. ${ }^{5,66,69}$ In practice, this rate depends significantly on the experience of the reviewer, the presence of very prodromal or terminal manifestations of disease, the lack of information about cytoreductive treatment and incomplete clinical data and mutation status.

\section{PRIMARY MYELOFIBROSIS}

Overt/advanced stages of PMF are clinically characterized by marked anemia, borderline to mild leukocytosis or leukopenia, slight thrombocytosis or even decrease in platelet counts, high levels of serum LDH, the presence of peripheral erythro and myeloblasts (leukoerythroblastosis), tear drop-shaped erythrocytes and gross splenomegaly (that is, myelofibrosis with myeloid metaplasia). ${ }^{11,93}$ All these features (Table 3 ) are not fully or only borderline expressed in prePMF (Table 4). ${ }^{7,94,95}$ Disease evolution can be easily observed in cohorts of patients followed over many years with sequential BM biopsy examinations ${ }^{96,97}$ thus elucidating the stepwise progression of PMF initiating from a prodromal (prefibrotic) stage without an increase in BM reticulin. ${ }^{7}$ Although the existence of a prodromal stage of PMF, that is, prePMF is supported by several studies, its clear-cut differentiation from ET and the diagnostic impact of clinical parameters have been questioned. ${ }^{13,89,91}$ Previous reports by a number of authorities are in full agreement that by strictly regarding the corresponding WHO criteria $^{2-4}$ an accurate discrimination between ET and prePMF can be accomplished that exerts a significant impact on presentation and clinical outcome. ${ }^{5-7,9,66,94,95,98,99}$ Altogether significant differences of presenting clinical data were observed between prePMF and ET regarding leukocyte counts (prePMF $>$ ET), Hb level (prePMF < ET), LDH values (prePMF $>$ ET), occurrence of a few peripheral erythro- or myeloblasts (pre$\mathrm{PMF}>\mathrm{ET}$ ) and finally, incidence of palpable splenomegaly (prePMF $>E T)^{5,6}$ In aggregate, in association with characteristic BM morphology, these clinical features allow an accurate distinction between prePMF and ET in the majority of cases provided in multicenter studies. $5,6,66,98$

The key features of prePMF usually include increased agematched BM cellularity, increased megakaryopoiesis of small to large megakaryocytes with atypical histotopography (endosteal translocation, dense clusters), and distinctive nuclear features (hypolobulation, clumsy-clould-like, maturation defects) and granulocytic proliferation, whereas erythropoiesis is usually reduced (Table 4). There is either a normal or only minor, amount of reticulin fibers present (grades $0 / 1$ ) contrasting advanced reticulin/collagen fibrosis (grades $2 / 3$ ) in overt PMF. ${ }^{67}$ According to several investigations by different groups, largely depended on methods and study design, consensus among diagnosis in distinguishing ET from prePMF diagnoses ranged from 53 to $88 \% .{ }^{5,6,9,66,69,72,73}$ Contradicting the agreement on morphological features the current 'minor clinical criteria' for the diagnosis of 
prePMF $^{3,4}$ sometimes impaired accurate classification and a clearcut separation of prePMF from ET. ${ }^{91}$

Finally, concerning the still controversial differentiation between ET and prePMF ${ }^{13-15,73,88,90-92}$ experts discuss that a more easy and precise definition of prePMF may be obtained by moving from a qualitative morphological description and a pattern recognition diagnostic process to a more quantitative evaluation of the morphological hallmarks and to follow a standardized procedural diagnostic pathway. ${ }^{71,90}$ Although this is a very convincing proposal that has to be regarded, considering the overall poor results of fiber grading by local pathologists ${ }^{100}$ in an international multicenter evaluation study, we should be aware that until now only few reference centers would be able to recognize and apply these key diagnostic features. All these shortcomings call for launching workshops and training sessions involving hematopathologists in reference centers to improve this unwanted situation we are still facing today. It is evident that this adverse situation may add to the conflict of opinion occasionally expressed concerning the overall value of BM morphology in MPN diagnosis.

\section{CONCLUSION}

Following the WHO classification the golden yardstick to accomplish a final diagnosis consists always of a synoptical approach including clinical and morphological findings and whenever possible, disease-relevant mutations. Keeping these postulates in mind the 2007/2008 updated WHO diagnostic criteria provided already a very solid basis now amenable to further improvement after more than 6 years of practical experience. The proposed amendments regard not only newly discovered molecular markers, but also the introduction of so-called $\mathrm{mPV}$ including a lowering of $\mathrm{Hb}$ and $\mathrm{Hct}$ values and an upgrading of BM morphology as major criterion. Moreover, there is a need for a more precise description of histopathology focused on fibrosis in ET and of minor clinical features in prePMF. For the future biological markers may probably be expected to be more useful for the discrimination of the different MPN subtypes in accordance with the histological BM pattern and corresponding clinical features.

\section{CONFLICT OF INTEREST}

The authors declare no conflict of interest.

\section{ACKNOWLEDGEMENTS}

AMV and TB were supported by a grant from Associazione Italiana per la Ricerca su Cancro (AIRC, Milano) 'Special Program Molecular Clinical Oncology 5×1000' to AGIMM (AIRC-Gruppo Italiano Malattie Mieloproliferative) (project \#1005).

\section{AUTHOR CONTRIBUTIONS}

TB, JT, AMV and AT contributed equally to this work and finally approved the text of the manuscript.

\section{REFERENCES}

1 Jaffe ES, Harris NL, Stein H, Vardiman JW. Tumours of Haematopoietic and Lymphoid Tissues. IARC Press: Lyon, France, 2001.

2 Tefferi A, Thiele J, Orazi A, Kvasnicka HM, Barbui T, Hanson CA et al. Proposals and rationale for revision of the World Health Organization diagnostic criteria for polycythemia vera, essential thrombocythemia, and primary myelofibrosis: recommendations from an ad hoc international expert panel. Blood 2007; 110 1092-1097.

3 Vardiman JW, Thiele J, Arber DA, Brunning RD, Borowitz MJ, Porwit A et al. The 2008 revision of the WHO classification of myeloid neoplasms and acute leukemia: rationale and important changes. Blood 2009; 114 937-951.
4 Swerdlow SH, Campo E, Harris NL, Jaffe ES, Pileri SA, Stein H et al. WHO Classification of Tumours of Haematopoietic and Lymphoid Tissues. IARC Press: Lyon, France, 2008.

5 Barbui T, Thiele J, Passamonti F, Rumi E, Boveri E, Ruggeri $\mathrm{M}$ et al. Survival and disease progression in essential thrombocythemia are significantly influenced by accurate morphologic diagnosis: an international study. J Clin Oncol 2011; 29 . 3179-3184.

6 Thiele J, Kvasnicka HM, Mullauer L, Buxhofer-Ausch V, Gisslinger B, Gisslinger H. Essential thrombocythemia versus early primary myelofibrosis: a multicenter study to validate the WHO classification. Blood 2011; 117: 5710-5718.

7 Barosi G, Rosti V, Bonetti E, Campanelli R, Carolei A, Catarsi P et al. Evidence that prefibrotic myelofibrosis is aligned along a clinical and biological continuum featuring primary myelofibrosis. PLoS One 2012; 7: e35631.

8 Ejerblad E, Kvasnicka HM, Thiele J, Andreasson B, Björkholm M, Löfvenberg E et al. Diagnosis according to World Health Organization determines the long-term prognosis in patients with myeloproliferative neoplasms treated with anagrelide: results of a prospective long-term follow-up. Hematology 2013; 18: 8-13.

9 Gisslinger H, Gotic M, Holowiecki J, Penka M, Thiele J, Kvasnicka HM et al. Anagrelide compared with hydroxyurea in WHO-classified essential thrombocythemia: the ANAHYDRET Study, a randomized controlled trial. Blood 2013; 121: 1720-1728.

10 Tefferi A, Rumi E, Finazzi G, Gisslinger $H$, Vannucchi AM, Rodeghiero $F$ et al. Survival and prognosis among 1,545 patients with contemporary polycythemia vera: an international study. Leukemia 2013; 27: 1874-1881.

11 Tefferi A. Primary myelofibrosis: 2014 update on diagnosis, risk-stratification, and management. Am J Hematol 2014; 89: 915-925.

12 Spivak JL, Silver RT. The revised World Health Organization diagnostic criteria for polycythemia vera, essential thrombocytosis, and primary myelofibrosis: an alternative proposal. Blood 2008; 112: 231-239.

13 Harrison CN, Bareford D, Butt N, Campbell P, Conneally E, Drummond M et al. Guidelines for investigation and management of adults and children presenting with a thrombocytosis. Br J Haematol 2010; 149: 352-375.

14 Harrison CN, Butt N, Campbell P, Conneally E, Drummond M, Green AR et al. Modification of British Committee for Standards in Haematology criteria for essential thrombocythaemia. Br J Haematol 2014; 167: 421-423.

15 Barbui T, Thiele J, Vannucchi AM, Tefferi A. Problems and pitfalls regarding WHO-defined diagnosis of early/prefibrotic primary myelofibrosis versus essential thrombocythemia. Leukemia 2013; 27: 1953-1958.

16 Alvarez-Larran A, Ancochea A, Gracia M, Climent F, Gracia-Pallarols F, Angona A et al. WHO-histological criteria for myeloproliferative neoplasms: reproducibility, diagnostic accuracy and correlation with gene mutations and clinical outcomes. Br J Haematol 2014; 166: 911-919.

17 Klampfl T, Gisslinger H, Harutyunyan AS, Nivarthi H, Rumi E, Milosevic JD et al. Somatic mutations of calreticulin in myeloproliferative neoplasms. $N$ Engl J Med 2013; 369: 2379-2390.

18 Nangalia J, Massie CE, Baxter EJ, Nice FL, Gundem G, Wedge DC et al. Somatic CALR mutations in myeloproliferative neoplasms with nonmutated JAK2. N Engl J Med 2013; 369: 2391-2405.

19 Tefferi A, Guglielmelli P, Larson DR, Finke C, Wassie EA, Pieri L et al. Long-term survival and blast transformation between molecularly-annotated essential thrombocythemia, polycythemia vera and primary myelofibrosis. Blood 2014; 124: $2507-2513$

20 Tefferi A. Novel mutations and their functional and clinical relevance in myeloproliferative neoplasms: JAK2, MPL, TET2, ASXL1, CBL, IDH and IKZF1. Leukemia 2010; 24: 1128-1138.

21 James C, Ugo V, Le Couédic JP, Staerk J, Delhommeau F, Lacout C et al. A unique clonal JAK2 mutation leading to constitutive signalling causes polycythaemia vera. Nature 2005; 434: 1144-1148.

22 Steensma DP, Dewald GW, Lasho TL, Powell HL, McClure RF, Levine RL et al. The JAK2 V617F activating tyrosine kinase mutation is an infrequent event in both "atypical" myeloproliferative disorders and myelodysplastic syndromes. Blood 2005; 106: 1207-1209.

23 Scott LM, Tong W, Levine RL, Scott MA, Beer PA, Stratton MR et al. JAK2 exon 12 mutations in polycythemia vera and idiopathic erythrocytosis. N Engl J Med 2007; 356: 459-468.

24 Pardanani A, Lasho TL, Finke C, Hanson CA, Tefferi A. Prevalence and clinicopathologic correlates of JAK2 exon 12 mutations in JAK2V617F-negative polycythemia vera. Leukemia 2007; 21: 1960-1963.

25 Tefferi A, Sirhan S, Lasho TL, Schwager SM, Li CY, Dingli D et al. Concomitant neutrophil JAK2 mutation screening and PRV-1 expression analysis in myeloproliferative disorders and secondary polycythaemia. Br J Haematol 2005; 131: 166-171.

26 Oh ST, Simonds EF, Jones C, Hale MB, Goltsev Y, Gibbs Jr KD et al. Novel mutations in the inhibitory adaptor protein LNK drive JAK-STAT signaling in patients with myeloproliferative neoplasms. Blood 2010; 116: 988-992. 
27 Broseus J, Park JH, Carillo S, Hermouet S, Girodon F. Presence of calreticulin mutations in JAK2-negative polycythemia vera. Blood 2014; 124: 3964-3966.

28 Tefferi A, Thiele J, Vardiman J, Vannucchi AM, Barbui T. An overview on CALR and CSF3R mutations and a proposal for revision of WHO diagnostic criteria for myeloproliferative neoplasms. Leukemia 2014; 28: 1407-1413.

29 Pikman Y, Lee BH, Mercher T, McDowell E, Ebert BL, Gozo M et al. MPLW515L is a novel somatic activating mutation in myelofibrosis with myeloid metaplasia. PLoS Med 2006; 3: e270.

30 Pardanani A, Lasho TL, Finke CM, Tefferi A. Infrequent occurrence of MPL exon 10 mutations in polycythemia vera and post-polycythemia vera myelofibrosis. Am J Hematol 2011; 86: 701-702.

31 Tefferi A, Lasho TL, Finke CM, Knudson RA, Ketterling R, Hanson CH et al. CALR vs JAK2 vs MPL-mutated or triple-negative myelofibrosis: clinical, cytogenetic and molecular comparisons. Leukemia 2014; 28: 1472-1477.

32 Hussein K, Bock O, Theophile K, von Neuhoff N, Buhr T, Schlué J et al. JAK2 (V617F) allele burden discriminates essential thrombocythemia from a subset of prefibrotic-stage primary myelofibrosis. Exp Hematol 2009; 37: 1186-1193.

33 Tefferi A, Lasho TL, Huang J, Finke C, Mesa RA, Li CY et al. Low JAK2V617F allele burden in primary myelofibrosis, compared to either a higher allele burden or unmutated status, is associated with inferior overall and leukemia-free survival. Leukemia 2008; 22: 756-761.

34 Guglielmelli P, Barosi G, Specchia G, Rambaldi A, Lo Coco F, Antonioli E et al. Identification of patients with poorer survival in primary myelofibrosis based on the burden of JAK2V617F mutated allele. Blood 2009; 114: 1477-1483.

35 Passamonti $F$, Rumi E, Pietra D, Elena C, Boveri E, Arcaini L et al. A prospective study of 338 patients with polycythemia vera: the impact of JAK2 (V617F) allele burden and leukocytosis on fibrotic or leukemic disease transformation and vascular complications. Leukemia 2010; 24: 1574-1579.

36 Tefferi A, Lasho TL, Schwager SM, Strand JS, Elliott M, Mesa R et al. The clinical phenotype of wild-type, heterozygous, and homozygous JAK2V617F in polycythemia vera. Cancer 2006; 106: 631-635.

37 Finazzi G, Carobbio A, Guglielmelli P, Cavalloni C, Salmoiraghi S, Vannucchi AM et al. Calreticulin mutation does not modify the IPSET score for predicting the risk of thrombosis among 1150 patients with essential thrombocythemia. Blood 2014; 124: 2611-2612.

38 Tefferi A, Wassie EA, Guglielmelli P, Gangat N, Belachew AA, Lasho TL et al. Type 1 versus Type 2 calreticulin mutations in essential thrombocythemia: a collaborative study of 1027 patients. Am J Hematol 2014; 89: 121-124.

39 Tefferi A, Lasho TL, Tischer A, Wassie EA, Finke CM, Belachew AA et al. The prognostic advantage of calreticulin mutations in myelofibrosis might be confined to type 1 or type 1-like CALR variants. Blood 2014; 124: 2465-2466.

40 Vannucchi AM, Lasho TL, Guglielmelli P, Biamonte F, Pardanani A, Pereira A et al. Mutations and prognosis in primary myelofibrosis. Leukemia 2013; 27: 1861-1869.

41 Tefferi A, Finke CM, Lasho TL, Wassie EA, Knudson R, Ketterling RP et al. U2AF1 mutations in primary myelofibrosis are strongly associated with anemia and thrombocytopenia despite clustering with JAK2V617F and normal karyotype. Leukemia 2014; 28: 431-433.

42 Laborde RR, Patnaik MM, Lasho TL, Finke CM, Hanson CA, Knudson RA et al. SETBP1 mutations in 415 patients with primary myelofibrosis or chronic myelomonocytic leukemia: independent prognostic impact in CMML. Leukemia 2013; 27: $2100-2102$

43 Genovese G, Kähler AK, Handsaker RE, Lindberg J, Rose SA, Bakhoum SF et al. Clonal hematopoiesis and blood-cancer risk inferred from blood DNA sequence. N Engl J Med 2014; 371: 2477-2487.

44 Jaiswal S, Fontanillas P, Flannick J, Manning A, Grauman PV, Mar BG et al. Age-related clonal hematopoiesis associated with adverse outcomes. $N$ Engl $J$ Med 2014; 371: 2488-2498.

45 Xie M, Lu C, Wang J, McLellan MD, Johnson KJ, Wendl MC et al. Age-related mutations associated with clonal hematopoietic expansion and malignancies. Nat Med 2014; 20: 1472-1478.

46 Guglielmelli P, Lasho TL, Rotunno G, Score J, Mannarelli C, Pancrazzi A et al. The number of prognostically detrimental mutations and prognosis in primary myelofibrosis: an international study of 797 patients. Leukemia 2014; 28: 1804-1810.

47 Chen E, Schneider RK, Breyfogle LJ, Rosen EA, Poveromo L, Elf S et al. Distinct effects of concomitant Jak2V617F expression and Tet2 loss in mice combine to promote disease progression in myeloproliferative neoplasms. Blood 2015; 125: 327-335.

48 Rampal R, Ahn J, Abdel-Wahab O, Nahas M, Wang K, Lipson D et al. Genomic and functional analysis of leukemic transformation of myeloproliferative neoplasms. Proc Natl Acad Sci USA 2014; 111: 5401-5410.

49 Ortmann CA, Kent DG, Nangalia J, Silber Y, Wedge DC, Grinfeld J et al. Effect of mutation order on myeloproliferative neoplasms. N Engl J Med 2015; 372 601-661.
50 Spivak JL. Polycythemia vera: myths, mechanisms, and management. Blood 2002; 100: 4272-4290.

51 McMullin MF, Bareford D, Campbell P, Green AR, Harrison C, Hunt B et al. Guidelines for the diagnosis, investigation and management of polycythemia/ erythrocytosis. Br J Haematol 2005; 130: 174-195.

52 Johansson $\mathrm{PL}$, Safai-Kutti S, Kutti J. An elevated venous haemoglobin concentration cannot be used as a surrogate marker for absolute erythrocytosis: a study of patients with polycythaemia vera and apparent polycythaemia. Br J Haematol 2005; 129: 701-705.

53 Tefferi A. The rise and fall of red cell mass measurement in polycythemia vera. Curr Hematol Rep 2005; 4: 213-217.

54 Cassinat B, Laguillier C, Gardin C, de Beco V, Burcheri S, Fenaux P et al. Classification of myeloproliferative disorders in the JAK2 era: is there a role for the red cell mass? Leukemia 2008; 22: 352-453.

55 Alvarez-Larrán A, Ancochea A, Angona A, Pedro C, García-Pallarols F, MartínezAvilés $L$ et al. Red cell mass measurement in patients with clinically suspected diagnosis of polycythemia vera or essential thrombocythemia. Haematologica 2012; 97: 1704-1707.

56 Silver RT, Chow W, Orazi A, Arles SP, Goldsmith SJ. Evaluation of WHO criteria for diagnosis of polycythemia vera: a prospective analysis. Blood 2013; 122: 1881-1886.

57 Barbui T, Thiele J, Gisslinger H, Finazzi G, Carobbio A, Rumi E et al. Masked polycythemia vera (mPV): results of an international study. Am J Hematol 2014; 89: $52-54$

58 Barbui T, Thiele J, Carobbio A, Gisslinger H, Finazzi G, Rumi E et al. Masked polycythemia vera diagnosed according to $\mathrm{WHO}$ and $\mathrm{BCSH}$ classification. Am J Hematol 2014; 89: 199-202.

59 Barbui T, Thiele J, Carobbio A, Guglielmelli P, Rambaldi A, Vannucchi AM et al. Discriminating between essential thrombocythemia and masked polycythemia vera in JAK2 mutated patients. Am J Hematol. 2014; 89: 588-590.

60 Barbui T, Thiele J, Kvasnicka HM, Carobbio A, Vannucchi AM, Tefferi A. Essential thrombocythemia with high hemoglobin levels according to the revised WHO classification. Leukemia 2014; 28: 2092-2094.

61 Lussana F, Carobbio A, Randi ML, Elena C, Rumi E, Finazzi G et al. A lower intensity of treatment may underlie the increased risk of thrombosis in young patients with masked polycythemia vera. Br J Haematol 2014; 167: 541-546.

62 Thiele J, Kvasnicka HM. Diagnostic impact of bone marrow histopathology in polycythemia vera (PV). Histol Histopathol 2005; 20: 317-328.

63 Thiele J, Kvasnicka HM, Diehl V. Initial (latent) polycythemia vera with thrombocytosis mimicking essential thrombocythemia. Acta Haematol 2005; 113: 213-219.

64 Gianelli U, lurlo A, Vener C, Moro A, Fermo E, Bianchi P et al. The significance of bone marrow biopsy and JAK2V617F mutation in the differential diagnosis between the "early" prepolycythemic phase of polycythemia vera and essential thrombocythemia. Am J Clin Pathol 2008; 130: 336-342.

65 Kvasnicka HM, Thiele J. Prodromal myeloproliferative neoplasms: The 2008 WHO classification. Am J Hematol 2010; 85: 62-66.

66 Gianelli U, Bossi A, Cortinovis I, Sabattini E, Tripodo C, Boveri E et al. Reproducibility of the WHO histological criteria for the diagnosis of Philadelphia chromosome-negative myeloproliferative neoplasms. Mod Pathol 2014; 27: 814-822.

67 Thiele J, Kvasnicka HM, Facchetti F, Franco V, van der Walt J, Orazi A. European consensus on grading bone marrow fibrosis and assessment of cellularity. Haematologica 2005; 90: 1128-1132.

68 Ellis JT, Peterson P. The bone marrow in polycythemia vera. Pathol Ann 1979; 1: 383-403.

69 Madelung AB, Bondo H, Stamp I, Loevgreen P, Nielsen SL, Falensteen A et al. World Health Organization-defined classification of myeloproliferative neoplasms: morphological reproducibility and clinical correlations--the Danish experience. Am J Hematol 2013; 88: 1012-1016.

70 Thiele J, Kvasnicka HM. Diagnostic differentiation of essential thrombocythaemia from thrombocythaemias associated with chronic idiopathic myelofibrosis by discriminate analysis of bone marrow features - a clinicopathological study on 272 patients. Histol Histopathol 2003; 18: 93-102.

71 Thiele J, Kvasnicka HM. The 2008 WHO diagnostic criteria for polycythemia vera, essential thrombocythemia, and primary myelofibrosis. Curr Hematol Malig Rep 2009; 4: 33-40

72 Florena AM, Tripodo C, lannitto E, Porcasi R, Ingrao S, Franco V. Value of bone marrow biopsy in the diagnosis of essential thrombocythemia. Haematologica 2004; 89: 911-919.

73 Gianelli U, Vener C, Raviele PR, Moro A, Savi F, Annaloro C et al. Essential thrombocythemia or chronic idiopathic myelofibrosis? A single-center study based on hematopoietic bone marrow histology. Leuk Lymphoma 2006; 47: 1774-1781. 
74 Pozdnyakova O, Wu K, Patki A, Rodig SJ, Thiele J, Hasserjian RP. High concordance in grading reticulin fibrosis and cellularity in patients with myeloproliferative neoplasms. Mod Pathol 2014; 27: 1447-1454.

75 Buhr T, Georgii A, Choritz H. Myelofibrosis in chronic myeloproliferative disorders. Incidence among subtypes according to the Hannover Classification. Pathol Res Pract 1993; 189: 121-132.

76 Georgii A, Buhr T, Buesche G, Kreft A, Choritz H. Classification and staging of $\mathrm{Ph}$-negative myeloproliferative disorders by histopathology from bone marrow biopsies. Leuk Lymphoma 1996; 22: 15-29.

77 Kreft A, Büche G, Ghalibafian M, Buhr T, Fischer T, Kirkpatrick CJ. The incidence of myelofibrosis in essential thrombocythaemia, polycythaemia vera and chronic idiopathic myelofibrosis: a retrospective evaluation of sequential bone marrow biopsies. Acta Haematol 2005; 113: 137-143.

78 Barbui T, Thiele J, Passamonti F, Rumi E, Boveri E, Randi ML et al. Initial bone marrow reticulin fibrosis in polycythemia vera exerts an impact on clinical outcome. Blood 2012; 119: 2239-2241.

79 Ellis JT, Peterson P, Geller SA, Rappaport H. Studies of the bone marrow in polycythemia vera and the evolution of myelofibrosis and second hematologic malignancies. Semin Hematol 1986; 23: 144-155.

80 Murphy S, Peterson P, lland $\mathrm{H}$, Laszlo J. Experience of the Polycythemia Vera Study Group with essential thrombocythemia: a final report on diagnostic criteria, survival, and leukemic transition by treatment. Semin Hematol 1997; 34: 29-39.

81 Regev A, Stark P, Blickstein D, Lahav M. Thrombotic complications in essential thrombocythemia with relatively low platelet counts. Am J Hematol 1997; 56: 168-172.

82 Lengfelder E, Hochhaus A, Kronawitter U, Höche D, Queisser W, Jahn-Eder M et al. Should a platelet limit of $6006109 / 1$ be used as a diagnostic criterion in essential thrombocythaemia? An analysis of the natural course including early stages. Br J Haematol 1998; 100: 15-23.

83 Sacchi S, Vinci G, Gugliotta L, Rupoli S, Gargantini L, Martinelli V et al. Diagnosis of essential thrombocythemia at platelet counts between 400 and 6006109/I Gruppo Italiano Malattie Mieloproliferative Croniche (GIMMC). Haematologica 2000; 85: 492-495.

84 Tefferi A, Hanson CA. Inwards DJ. How to interpret and pursue an abnormal complete blood cell count in adults. Mayo Clin Proc 2005; 80: 923-936.

85 Griesshammer M, Bangerter M, Sauer T, Wennauer R, Bergmann L, Heimpel H. Aetiology and clinical significance of thrombocytosis: analysis of 732 patients with an elevated platelet count. J Intern Med 1999; 245: 295-300.

86 Schafer Al. Thrombocytosis. N Engl J Med 2004; 350: 1211-1219.

87 Wilkins BS, Radia D, Woodley C, Farhi SE, Keohane C, Harrison CN. Resolution of bone marrow fibrosis in a patient receiving JAK1/JAK2 inhibitor treatment with ruxolitinib. Haematologica 2013; 98: 1872-1876.

88 Brousseau M, Parot-Schinkel E, Moles MP, Boyer F, Hunault M, Rousselet MC. Practical application and clinical impact of the WHO histopathological criteria on bone marrow biopsy for the diagnosis of essential thrombocythemia versus prefibrotic primary myelofibrosis. Histopathology 2010; 56: 758-767.
89 Campbell PJ, Bareford D, Erber WN, Wilkins BS, Wright P, Buck G et al. Reticulin accumulation in essential thrombocythemia: prognostic significance and relationship to therapy. J Clin Oncol 2009; 27: 2991-2999.

90 Thiele J, Kvasnicka HM, Diehl V. Standardization of bone marrow features - does it work in hematopathology for histological discrimination of different disease patterns? Histol Histopathol 2005; 20: 633-644.

91 Buhr T, Hebeda K, Kaloutsi V, Porwit A, Van Der Walt J, Kreipe HH. European Bone Marrow Working Group trial on reproducibility of WHO criteria to discriminate essential thrombocythemia from prefibrotic primary myelofibrosis. Haematologica 2012; 97: 360-365.

92 Koopmans SM, Bot FJ, Lam KH, van Marion AM, de Raeve H, Hebeda KM Reproducibility of histologic classification in nonfibrotic myeloproliferative neoplasia. Am J Clin Pathol 2011; 136: 618-624.

93 Barosi G. Myelofibrosis with myeloid metaplasia: diagnostic definition and prognostic classification for clinical studies and treatment guidelines. J Clin Oncol 1999; 17: 2954-2970.

94 Kvasnicka HM, Thiele J. The impact of clinicopathological studies on staging and survival in essential thrombocythemia, chronic idiopathic myelofibrosis, and polycythemia rubra vera. Semin Thromb Hemost 2006; 32: 362-371.

95 Thiele J, Kvasnicka HM. Grade of bone marrow fibrosis is associated with relevant hematological findings-a clinicopathological study on 865 patients with chronic idiopathic myelofibrosis. Ann Hematol 2006; 85: 226-232.

96 Buhr T, Büsche G, Choritz H, Länger F, Kreipe H. Evolution of myelofibrosis in chronic idiopathic myelofibrosis as evidenced in sequential bone marrow biopsy specimens. Am J Clin Pathol 2003; 119: 152-158.

97 Thiele J, Kvasnicka HM, Schmitt-Graeff A, Diehl V. Dynamics of fibrosis in chronic idiopathic (primary) myelofibrosis during therapy: a follow-up study on 309 patients. Leuk Lymphoma 2003; 44: 949-953.

98 Barosi G. Essential thrombocythemia vs. early/prefibrotic myelofibrosis: why does it matter. Best Pract Res Clin Haematol 2014; 27: 129-140.

99 Finazzi G, Carobbio A, Thiele J, Passamonti F, Rumi E, Ruggeri M et al. Incidence and risk factors for bleeding in 1104 patients with essential thrombocythemia or prefibrotic myelofibrosis diagnosed according to the 2008 WHO criteria. Leukemia 2012; 26: 716-719.

100 Pozdnyakova O, Rodig S, Bhandarkar S, Wu K, Thiele J, Hasserjian R. The importance of central pathology review in international trials: a comparison of local versus central bone marrow reticulin grading. Leukemia 2015; 29: 241-244.

(c) (i)

This work is licensed under a Creative Commons Attribution 4.0 International License. The images or other third party material in this article are included in the article's Creative Commons license, unless indicated otherwise in the credit line; if the material is not included under the Creative Commons license, users will need to obtain permission from the license holder to reproduce the material. To view a copy of this license, visit http://creativecommons.org/licenses/ by/4.0/ 